\title{
Value of Music Education to the Development of Preschool Children
}

\author{
QuanlongQiao ${ }^{1, a}$ \\ ${ }^{1}$ Xi'an University, Xi'an, Shaanxi, China, 710065 \\ ${ }^{a}$ email
}

Keywords: Preschool Children, Music Education, Children’s Development

\begin{abstract}
Music education is an indispensable organic component of quality education, which plays an important role in the education of preschool children. This paper gives the concept of preschool music education, and expounds the important function of music education in the fields of physical and mental development, the cognitive development and the emotion and will development of preschool children in order to give right theoretical direction of preschool music education to vast kindergarten teachers and parents.
\end{abstract}

\section{Introduction}

As a part of the preschool education, the preschool music educationhas some characteristics in common with other kind of education. However, it also has its special characteristics that reflect the two aspects: on the one hand, it refers to the children's music; on the other hand refers to the education of music, suggesting that we cannot understand the music education of preschool children a pure music education knowledge, skills, pure art, nor from the special law of the psychological development of children's music and music art itself to the law of the implementation of music education, only the two aspects together organically, can really make preschool music education become established on the basis of music art, children actively participate in music practice activities. Music and children's development is also closely linked, children born with love and explore the music of music, music is one of the earliest social experience of children.It is a part of children's life. To the music as the value orientation of music education of preschool children, attention, emphasize the main body function of music.The continuation and development of the initial stage of human music culture will lay the foundation for the realization of music itself inherent value and function of music.

Nowadays music education has been attached great importance to the development of science and health education. Music in children's education, there is a distinction between other disciplines of the dominant music as an independent discipline, and other disciplines have generally consistent with the basic properties. Therefore, the music education as a dedicated to training disciplines of music as a key to focus on the different effect and the effect of music education also will be very different. The purpose of the former is to cultivate children's professional music knowledge and skills, focusing on the nature of music education; the latter is based on the comprehensive development of the child to realize the education ultimate objective. By analyzing and summarizing the two views are not in opposition to each other, exactly is music education the coexistence of two dimensions or levels cannot be both isolated up to carry on the inspection from the musical subject in education level point of view, culture view of music education of children's musical skills and knowledge, attributes of music as a basic subject, while the latter is on this point of view, expand and sublimate. The ultimate goal of education is all-round development and shaping a sound personality. 


\section{Music Education Can Promote Physical and Mental Development of Preschool Children}

Promote Physical Development. The most obvious role of music in children's education is to promote the healthy development of children. Music curriculum education mainly acts on children's senses. It includes hearing, music through the auditory stimulation, the brain to give a certain signal, the central nervous system of the brain to the music signal processing to feedback. Music course of training, an increase of the opportunities and space for the children to contact with music, by listening to music and enjoy music, exercise the brain ability to react to things, active in the cerebral cortex and promote the flexible thinking medical studies have shown that music for children's physical development plays a significant role in promoting, can improve the child's brain response ability and physical coordination. In the early stage of study, the music learning of children is very little. In the accompanying music acting activities and musical instruments playing activities, children can exercise the corresponding part of the size of the muscles, bones and ligaments, improve nervous system reaction speed and coordination, and enhance the tolerance of the heart and lungs, and other organs. Children are more likely to get fit body shape, correct posture and good development. Even singing activities can promote the development of the vocal organs, organs and respiratory organs.

Promote Psychological Development.There is a close relationship between music activities and physical and mental health of children, and psychological activities are the main influencing factors of physical health. Modern physiological and psychological research has confirmed that "emotional" this mental state will be accompanied by a series of physiological changes, such as muscle, vascular, visceral and endocrine organ function will change with the changes of mood. With the development of science, people have been able to through the instrument of the music of the physiological responses to make quantitative analysis to prove what kind of music can produce what kind of physiological stimulation and the results of these studies has begun to be applied into the correction of chronic disease treatment, physical and mental rehabilitation, children with developmental disorders etc. fields. It is possible to improve or maintain physical and mental health by adjusting the physiological state in order to improve or maintain physical and mental health. Preschool children naturally active demand easily in the music activities satisfied; in music rhythm elements can save energy consumption, so that the body's internal environment of the formation of the best state, physiological needs of self easily satisfied. Music is easy to produce closer interpersonal relationships. At the same time, children will get free imagination.

\section{Music Education Can Promote Cognitive Development of Preschool Children}

Strengthen Perception Ability. In the child's education process, emphasizing the ability of a variety of comprehensive training and exercise, the purpose is to promote the comprehensive improvement of their ability. The nervous system of the cerebral cortex, often the most responsive to the most responsive signal response, music education is to help children improve the language system, language ability to improve, enhance the sensitivity of music. Hearing ability in addition to the influence of innate factors, acquired education factors also play an important role in the impact of. Similarly, in music education, children learn the strength of the resolution of sound level, length, volume, different voice tone, timbre etc. will make children's auditory acuity continues to improve, and hearing the development of children's intelligence development and future lifelong learning are affected. Early for pre-school children provides various to participate in the activities of the music the opportunity and the environment, and in activities consciously guide their attention on the study of the auditory, preschool children's perception of sound ability and consciousness is can be 
improved. Human hearing organs can get continuously improved in the process of long-term conscious use.

Strengthen Memory Ability.The training of children's memory ability is an important part of preschool education. It not only needs to rely on auditory discrimination, but also for the need to pay attention to the ability of the hearing. In the process of preschool music education, the ability of auditory memory is often shown as the ability to reproduce music. In the process of music appreciation, music elements through music playing for various kinds of music image transformation, then the expression of music content. Therefore, music and memory abilities affect the children's perception of music ability early is the best children's hearing ability training, children's music learning and experiences can make them in the music activities enhance the auditory sensitivity and development of auditory perception and memory representation. Related preschool music education experts said: small age children in activities of music education can also exhibit a strong musical memory, such as when you hear the familiar rhythm of music sound, you can immediately humming a tune. The children will get music and memory abilities development. The training of auditory ability is not only related to auditory perception, auditory discrimination, auditory attention ability, but also in the auditory memory ability. The ability of auditory memory refers to the ability of memorizing music and reproducing music. Therefore, music memory ability directly affects the ability of imagination of music.

Strengthen Imagination Ability. When children enjoy the rich appeal, performance of the music works, they often cannot help to be intoxicated with the fun of the imagination, the music has a certain resonance. In psychology, the thinking activities are summarized as three forms of intuition thinking, specific image thinking and abstract concept thinking, and music education has a certain relationship with them. Among them, the intuitive thinking is directly related to children's music action, children in the process of imitating adult singing or doing action, thinking and learning. Children can also gradually accumulate on the basis of the preliminary summary of the ability to judge the ability, such as the ability to distinguish the style of music, the nature of the music, know the music style, the initial establishment of the experience of music. Although children's perception of music, understanding with obvious intuitive, image, and children's musical way of thinking is to an external, intuition, the image of assurance. However, thinking of the music itself is inclusive of the thinking in images, inclusive of the abstract thinking. Teachers and adults is necessary in music education activities by every opportunity and means to help a child on the relationship between the music and objective things and understanding, gradually establish initial musical abstraction. Music itself is a kind of abstract personalized art, the music of the feeling and experiences no fixed, uniform standard answer, so it can give children to provide a broader space for creation. In the process of music education, children's physical and psychological conditions, as well as the uniqueness of the music itself provides a good opportunity for the development and cultivation of creative thinking in children.

\section{Music Education Can Promote Emotion and Willpower Development of Preschool Children}

Cultivate Preschool Children's Emotion. Emotion refers to the social needswhich have been met and the experience which is accompanied by people's cognition and produced. It also includes the understanding of the development to promote or hinder, visible, cultivating positive affective education is also one of the most important tasks. Music is by melody, sound and other means to express the delicate mental activities and emotions of art for human beings, the biggest characteristic of the art of music is to love moving, emotional, as musician Stravinsky said, music is the emotionand have no emotion to have music. Therefore, through music education to promote the 
development of children's emotion has become the meaning of the music itself. We know, early childhood science is in personal feelings from junior to senior development gradually the important stage, with the children's social intercourse activity increasing, emotional experience in the increasingly rich and differentiation become delicate, rich emotion of music activities has gradually become can promote children's emotional development is one of the effective means. Music can help children to establish their own feelings, but also to help children with their emotional communication, and to communicate with other people's feelings. A good music work or a successful music education activities can make children's emotional resonance of music, so as to cultivate and inspire children's good emotional. In addition, children in music education activities can be widely exposed to the performance of different emotions. They will gradually understand the love, gentleness, compassion, pride of the collective spirit, hate ugly and the pursuit of beauty and goodness.

Cultivate Preschool Children's Willpower.Willpower is a kind of psychological process in which people can stimulate, maintain and restrain their behavior according to a certain purpose. Music education is a kind of practical activities, whether it is learning to sing or play a musical instrument, it is required to have a certain music technology, etc. For young children, especially for young children, there is no persistent spirit of hard work and courage to overcome difficulties, will, is unable to achieve the goal. In music activities, children as an individual, not only need to control their behavior to match the music, but also to coordinate their relationship with others, so as to make music and children to achieve harmony and unity. Regardless of learning to sing, learning to do the rhythmic movement, or learning to play with musical instruments, are increasingly becoming a kind of action with a clear purpose. Especially for some of the more difficult music skills learning, there is no persistent hard learning is unable to achieve the goal of determining the. In most cases, children are able to try to follow the teacher's accompaniment to better cooperate with others, can also according to the requirements of teachers to objective observation, memory, imagination and thinking, expression activity. The willpower of preschool children needs to be cultivated by music.

\section{Conclusion}

As part of the art education, music education exerts an imperceptible influence on children's learning and growing. Kindergarten teachers should command the importance of music education to preschool children and spread these ideas to the children's parents to promote the healthy and happy growth of preschool childrenthrough music education.

\section{References}

[1] Jiang Manman, Northern Music, Vol. 22 (2014) No 8, p.138

[2] Lyu Lin, Journal of Xianning University, Vol. 32 (2012) No 7,p.116-117

[3] Mou Danni, Journal of Jiamusi Vocational, Vol. 31 (2015) No 2,p.134-135

[4]Xiao Sufen, Art Education, Vol. 35 (2013) No 10,p.49-51

乔全龙 13891828358 陕西西安市科技六路一号西安文理学院 